\title{
If Sugar Is Addictive... What Does It Mean for the Law?
}

\author{
Ashley Gearhardt, Michael Roberts, and Marice Ashe
}

$\mathbf{S}$ ugar consumption has long been linked with a host of chronic health problems, including obesity, diabetes, and cardiovascular disease. To reduce Americans' intake, many have called for taxing sugary products or limiting access in certain environments like schools and workplaces. These sometimes controversial calls for new public policy to curb consumption may soon be eclipsed by newly emerging links between sugar and addiction.

Attaching the label "addictive" to a substance like sugar, which is necessary for human life, challenges widely held beliefs about addiction. But the extraordinary increase in sugar consumption during the past century, with related tripling of chronic diseases like obesity and diabetes, means our common understandings may be outdated.

Part I of this paper will define "addiction" - especially as it relates to what was once a naturally occurring food nutrient and now is a highly concentrated food additive - and present evidence of the addictive potential of sugar. Part II will explore the legal implications if sufficient evidence demonstrates that sugar is indeed addictive.

\section{Defining Addiction}

Addictive substances were historically conceptualized by the intensity of the intoxication syndrome (e.g., how high someone gets), the severity of the

Ashley Gearhardt, Ph.D., is an Assistant Professor of psychology at the University of Michigan. Her research focuses on the overlap between addictive and eating behaviors. Michael Roberts, J.D., is an Adjunct Professor at the University of California, Los Angeles School of Law and the Director of the Center for Food Law and Policy. Marice Ashe, J.D., M.P.H., is the founder and chief executive officer of ChangeLab Solutions offering legal and policy solutions for the common good. withdrawal symptoms, and the illegality of the substance. Tobacco-related disease is the leading cause of preventable death in the United States, ${ }^{1}$ yet nicotine addiction differs significantly from earlier perceptions about addiction. Nicotine intoxication is not particularly mind-altering (e.g., you can legally drive your car while smoking), nicotine withdrawal is relatively mild (it is not life-threatening nor does it require hospitalization), and nicotine is legal to procure and use in most cases. The acknowledgement that nicotine was not just habit forming or dangerous but also an addictive substance substantially reshaped scientific and public perceptions of addiction. ${ }^{2}$

Although intoxication and physical dependence are still important components of addiction, the new focus highlights the importance of (1) the inability of the individual to successfully cut down or abstain from the substance, (2) continued use despite negative consequences, and (3) diminished control over consumption of the substance. ${ }^{3}$ This shift in understanding has furthered interest in the addictive potential of nontraditional substances and behaviors, like gambling. The rapidly increasing rates of obesity, combined with the high failure rates of obesity treatment, has led to the hypothesis that ultra-processed foods (often high in sugar) may be capable of triggering an addictive process.

\section{The Creation of an Addictive Substance}

A central component to understanding addiction is the role of the substance. Unlike other psychiatric disorders that focus mostly on individual risk factors (e.g., negative affect, genetic risk), addiction places an additional emphasis on the attributes of the substance that contribute to the pathology. Addictive substances rarely occur in nature; they are typically created 
through processing. For example, the coca leaf has historically been a staple of Latin American cultures. When chewed or seeped as a tea, the coca leaf provides stimulating effects akin to a cup of coffee and has minimal addictive potential. Refining the coca leaf to become more potent and more quickly absorbed into the system produces cocaine, and the addictive potential increases exponentially ${ }^{4}$ as the substance "hijacks" the reward system for at-risk individuals. With further processing cocaine can become crack cocaine, which is cheaper to make and easier to distribute. The combination of low price, greater accessibility, and high addictive potential leads to widespread problematic use and elevated public health costs. is enhanced by the cheapness, accessibility, and heavy marketing of these products, thus increasing the public health burden.

\section{Evidence of Sugar's Addictive Potential}

Research designed to test sugar's addictive potential is relatively new and the validity of this concept is debated, but this field is growing rapidly. The majority of evidence linking sugar and addiction comes from animal models. Rats given intermittent access to sugar are more likely to binge, to consume progressively larger quantities of sugar, to show behavioral and biological indicators of withdrawal when sugar is removed and to exhibit a stronger response

\section{Today, many foods in the Western diet have artificially high levels of sugar} added during processing (in addition to other rewarding ingredients, like fat and salt); these foods are also often stripped of fiber, water, and protein. In other words, these naturally rewarding foods have been altered in such a way that significantly increases reward potency (as well as increases the speed of the substances' entry into the system), and may increase risk for the development of a potentially addictive substance - in this case, unnaturally high-sugar foods. The negative impact of any addictive potential associated with these foods is enhanced by the cheapness, accessibility, and heavy marketing of these products, thus increasing the public health burden.

Our food supply has undergone a similar transformation. Historically, foods with higher caloric values (like those containing sugar) were relatively rare. To enhance motivation to seek out foods that would increase the chance of survival in times of famine, greater reward responses likely evolved for calorie-rich ingredients, like sugar. ${ }^{5}$ Some foods are naturally high in sugar, such as fruits, and these food types are often considered "palatable" or pleasurable to eat. Sugar in its naturally occurring form is typically accompanied with fiber and/or water, which slows absorption into the system. Today, many foods in the Western diet have artificially high levels of sugar added during processing (in addition to other rewarding ingredients, like fat and salt); these foods are also often stripped of fiber, water, and protein. In other words, these naturally rewarding foods have been altered in such a way that significantly increases reward potency (as well as increases the speed of the substances' entry into the system), and may increase risk for the development of a potentially addictive substance - in this case, unnaturally high-sugar foods. ${ }^{6}$ The negative impact of any addictive potential associated with these foods to drugs and alcohol.7 Additional research has identified that when rats are forced to choose between sugar and drugs of abuse (e.g., cocaine), they exhibit a greater preference for the sugar, even when they are physiologically dependent on the drug. ${ }^{8}$ Researchers compared rats given a standard chow diet with rats maintained on a diet of highly palatable foods (most of which were high in sugar, fat, and salt); the latter group exhibited changes in the reward system implicated in addiction. ${ }^{9}$ They would also seek out these potentially addictive foods despite receiving electric shocks while doing so, another classic behavioral indicator of addiction. ${ }^{10}$

Research into sugar's addictive potential is even newer in humans, but there is evidence to support this concept. In humans, drugs of abuse and highly palatable foods activate similar brain systems and obesity and binge eating disorder (BED) are related to similar patterns of neural activation implicated in substance dependence. ${ }^{11}$ For example, obese and substancedependent individuals both display increased activity in regions of the brain related to cravings when they view food and substance cues, respectively. ${ }^{12}$ Addi- 
tionally, obesity and addiction are linked to reduced activation in reward-related and control-related brain regions when consuming food or substances, which might reflect the role of tolerance and loss of control across both disorders. ${ }^{13}$ This is consistent with an overlap in the behaviors related to both substance dependence and problematic eating (e.g., craving, relapse, continued use despite negative consequences). ${ }^{14}$

\section{Legal Implications}

Assessing the legal implications of sugar-addiction research is challenging given the unique roles that food and sugar play in Americans' lives: food sustains life and reflects cultural values, while sugar is ubiquitous in the American food supply and is in many respects a cultural icon. Still, an assessment is warranted. Legal historian Lawrence M. Friedman has noted that modern law mirrors society and evolves with the times: because it is up to date, it functions as a tool to push towards a definite goal. ${ }^{15}$ If the goal of sugar-addiction research is to lessen the consumption of sugar, then what should be the response of law? How should the law address sugar's potentially addictive properties? What legal tools should be employed?

A complete analysis of these questions is beyond the purview of this article. Instead, the objective here is to propose an analytical framework that recognizes the role of politics and regulatory philosophy in evaluating the legal tools that could be employed if sugar-addiction research gains traction. This limited analysis seeks to raise core issues and stimulate a more robust and thorough discussion.

\section{Politics: Stakeholder Interests}

The often-divergent interests of three distinctive stakeholders - public health officials, the food industry, and consumers - are central to the analysis of politically viable legal tools. In response to evidence suggesting that sugary beverages contribute to the obesity epidemic, ${ }^{16}$ public health officials often call for more aggressive controls on unhealthy foods in the American diet, even without conclusive proof of sugar's addictiveness. The food industry contends that isolating a singular food product or ingredient like sugar and subjecting it to regulation is simplistic; the industry asserts that because obesity is a complex and multifaceted problem that requires life-style solutions, a single type of food ought not to be penalized. The food industry demonstrated its resistance to regulation with its recent objections to the U.S. Food and Drug Administration's plan to test consumer responses to changes in the Nutrition Facts labels, which included a declaration of added sugar amounts. ${ }^{17}$ However, as evidence of addiction emerges, the food industry could respond by self-regulation: some beverage companies, for example, recently began posting nutrition information next to vending machines in Chicago and San Antonio. ${ }^{18}$

Consumer interests are more difficult to pin down. Consumers value the freedom to choose what they want to eat, but food regulations often underestimate consumers' desire for information. ${ }^{19}$ Once consumers receive information, there is concern over their capacity to interpret and effectively use it. If sugar is proven to be addictive, then regulatory decisions should determine how much information should be provided to consumers and in what form (i.e., facts panels, warning labels, or some other dissemination device) in order to be used effectively. In addition to choice and information, other issues, such as access and price, are important to consumers.

\section{Regulatory Philosophy: Sharpening the \\ Political Debate}

The basic tenets of public health lie at the heart of the debate over sugar addiction and to the potential for regulation. Four criteria have been posed to justify the regulation of alcohol: its unavoidability or pervasiveness in our culture, toxicity, potential for abuse, and negative impact on society. ${ }^{20}$ Even if sugar meets these criteria, the issue arises as to whether sugar should be regulated like alcohol or drugs or whether there is justification for regulating addictive substances in different ways. ${ }^{21}$ Several variables need to be carefully considered: whether there are possible negative aspects of prohibiting sugary products (i.e., soda ban in California schools); whether civil liberties might be violated by proposed regulations; and how regulations might impinge on traditional values of personal responsibility. ${ }^{22}$

The debate over these issues is likely to ignite a political firestorm and pit public health interests against industry concerns that civil liberties and personal choice could be jeopardized. ${ }^{23}$ The challenge for public health officials is to judge what regulatory steps and tools are suitable and practical in such a charged political environment.

\section{Legal Tools}

Regulatory tools and approaches are diverse and include labeling (disclosure and warning), advertising restrictions, taxes (special excise duties, value-added taxes and sales taxes), ${ }^{24}$ product bans or restrictions, litigation (especially class action litigation), self-regulation, a reduction of farm subsidies and sugar programs, and the development of education programs. Thoughtful analysis of the implications of these tools must consider several issues, including the following: 
whether advertising restrictions on sugary food products violate the First Amendment; ${ }^{25}$ whether taxes or bans on products change consumer behavior or are an unnecessary burden and intrusion on consumers; whether a reduction of farm subsidies and sugar programs effectively reduces sugar consumption; and whether class action litigation furthers public health objectives by changing the production and marketing of sugar products and the consumption habits of consumers. Finally, consideration should be given to the potential outcome of the implementation of these tools: the stigma attached to sugar products and overweight consumers.

As research continues to explore the possibility that sugar could be an addictive substance, it behooves policy analysts to consider the political and philosophical issues involved in pursuing various regulatory approaches. Recognizing and addressing these issues will support cogent decision making about the use of legal tools to decrease sugar consumption and improve the health of American consumers.

\section{References}

1. A. H. Mokdad, J. S. Marks, M. F. Stroup, and J. L. Gerberding, "Actual Causes of Death in the United States," JAMA 291, no. 10 (2004): 1238-1245.

2. I. P. Stolerman and J. J. Jarvis, "The Scientific Case That Nicotine Is Addictive," Psychopharmacology 117, no. 1 (1995): 2-10.

3. M. N. Potenza, "Should Addictive Disorders Include Non-Substance-Related Conditions?" Addiction 101, Supp. 1 (2006): 142-151.

4. K. Verebey and M. S. Gold, "From Coca Leaves to Crack: The Effects of Dose and Routes of Administration in Abuse Liability," Psychiatric Annals 18, no. 9 (1988): 513-520.

5. S. B. Eaton, "The Ancestral Diet: What Was It and Should It Be a Paradigm for Contemporary Nutrition?" Proceedings of the Nutrition Society 65, no. 1 (2006): 1-6.

6. A. N. Gearhardt et al., "The Addiction Potential of Hyperpalatable Foods," Current Drug Abuse Revieres 4, no. 3 (2011): 140-145.

7. H. Ziauddeen, S. Farooqi, and P.C. Fletcher, "Obesity and the Brain: How Convincing Is the Addiction Model?" Nature Reviews Neuroscience 13, no. 4 (2012): 279-286; N. M. Avena, P. Rada, and B. G. Hoebel, "Evidence for Sugar Addiction: Behavioral and Neurochemical Effects of Intermittent, Excessive Sugar Intake," Neuroscience Biobehavioral Review 32, no. 1 (2008): 20-39.

8. M. Lenoir et al., "Intense Sweetness Surpasses Cocaine Reward," PLoS ONE 2, no. 8 (2007): e698.

9. P. M. Johnson and P. J. Kenny, "Dopamine D2 Receptors in Addiction-Like Reward Dysfunction and Compulsive Eating in Obese Rats," Nature Neuroscience 13, no. 5 (2010): 635-641.

10. Id.

11. N. D. Volkow et al., "Overlapping Neuronal Circuits in Addiction and Obesity: Evidence of Systems Pathology," Philosophi- cal Transactions of the Royal Society 363, no. 1507 (2008): 3191-3200.

12. D. W. Tang et al., "Food and Drug Cues Activate Similar Brain Regions: A Meta-Analysis of Functional MRI Studies," Physiology छ Behavior 106, no. 3 (2012): 317-324.

13. E. Stice et al., "Relation of Obesity to Consummatory and Anticipatory Food Reward," Physiology छ Behavior 97, no. 5 (2009): 551-560.

14. M. S. Gold, K. Frost-Pineda, and W. S. Jacobs, "Overeating, Binge Eating, and Eating Disorders as Addictions," Psychiatric Annals 33, no. 2 (2003): 117-12215.

15. L. M. Friedman, A History of American Law: Third Edition (New York: Touchtone, 2005): at XII.

16. D. Ludwig, K. Peterson, and S. Gortmaker, "Relation between Consumption of Sugar Sweetened Drinks and Childhood Obesity: A Prospective, Observational Study," The Lancet 357, no. 9255 (2001): 505-508.

17. J. Murphy, "FDA's Added Sugars Study Prompts Complaints from Food Industry," Food Chemical Neres (London), August 10,2012 , at 1 .

18. S. Strom, "Pepsi and Coke to Post Calories of Drinks Sold in Vending Machines," New York Times, October 8, 2012.

19. D. A. Kysar, "Preferences for Processes: The Process/Product Distinction and the Regulations of Consumer Choice," Harvard Law Review 118, no. 2 (2004): 525-529. 20.

20.T. Babor et al., Alcohol: No Ordinary Commodity Research and Public Policy (New York: Oxford University Press, 2010): at 5.

21. F. Mena and R. Hobbs, "Narcophobia: Drugs Prohibition and the Generation of Human Rights Abuses," Trends in Organized Crime 13, no. 1 (2010): 60-74; P. Smith, "Drugs, Morality, and the Law," Journal of Applied Philosophy 19, no. 3 (2002): 233244. 22.

22. K. Brownell et al., "Personal Responsibility and Obesity: A Constructive Approach to a Controversial Issue," Health Affairs 29 no. 3 (2010): 3379-387. 23.

23. M. Daum, "A Feeding Frenzy," Los Angeles Times, March 3, 2011.

24. R. H. Lustig et al., "Public Health: the Toxic Truth about Sugar," Nature 482, no. 7383 (2012): 27-29; FTC CDC FDA and USDA, Interagency Working Group on Food Marketed to Children: Proposed Nutrition Principles, to Guide Industry Self-Regulatory Efforts, Project No. P094513; B. Silverglade and I. R. Heller, Food Labeling Chaos the Case for Reform, (Washington, D.C. Center for Science in the Public Interest: March 2010); see Cal. Educ. Code $\$ 49431.5(2006)$; and also Ackerman v. The CocaCola Co., No. 09-cv-0395, 2010 WL 2925955 (E.D.N.Y. Jul. 21, 2010).

25. See K. M. Sullivan, The Interagency Working Group's Preliminary Proposed Nutrition Principles to Guide Industry Self-Regulatory Efforts: Constitutional Issues, Appendix A in: Comments of Viacom before the Federal Trade Commission (July 14, 2011), available at <http://www.ftc.gov/os/comments/ foodmarketedchildren/07884-80045.pdf> (last visited January 3, 2013) (First Amendment concerns "would unquestionably invalidate" mandatory government restrictions on food marketing to children); but cf., G. D. Allison et al., Open Letter on the First Amendment and the Interagency Working Group Principles to FTC, CDC, FDA, USDA, and the White House, September 6, 2011, available at <http://changelabsolutions.org/sites/ changelabsolutions.org/files/IWG_1ALawProfLetter_20111012. pdf> (last visited January 3, 2013) (Nutrition principles, which are designed to guide industry self-regulatory efforts, do not restrain or compel anyone's speech.). 